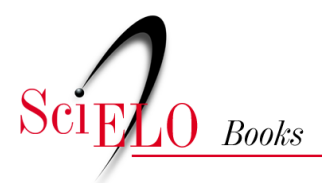

Parte II - Características e manifestações do modelo brasileiro: algumas reflexões

\title{
Políticas públicas municipais de emprego, trabalho e renda: um panorama do investimento nos municípios do Noroeste do estado do Rio Grande do Sul
}

\author{
Ângela Mattiazzi \\ Rodrigo Severo
}

\section{SciELO Books / SciELO Livros / SciELO Libros}

MATTIAZZI, A., and SEVERO, R. Políticas públicas municipais de emprego, trabalho e renda: um panorama do investimento nos municípios do Noroeste do estado do Rio Grande do Sul. In: ROTTA, E., LOPES, H. C., and ROSSINI, N., eds. O modelo de desenvolvimento brasileiro das primeiras décadas do século XXI: aportes para o debate [online]. Chapecó: Editora UFFS, 2018, pp. 356-378. ISBN: 978-85-64905-82-5. https://doi.org/10.7476/9788564905832.0017.

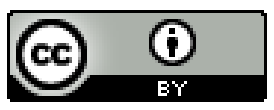

All the contents of this work, except where otherwise noted, is licensed under a Creative Commons Attribution 4.0 International license.

Todo o conteúdo deste trabalho, exceto quando houver ressalva, é publicado sob a licença Creative Commons Atribição 4.0.

Todo el contenido de esta obra, excepto donde se indique lo contrario, está bajo licencia de la licencia Creative Commons Reconocimento 4.0. 


\title{
POLÍTICAS PÚBLICAS MUNICIPAIS DE EMPREGO, TRABALHO E RENDA: UM PANORAMA DO INVESTIMENTO NOS MUNICÍPIOS DO NOROESTE DO ESTADO DO RIO GRANDE DO SUL
}

\author{
Ângela Mattiazzi \\ Rodrigo Severo
}

\section{INTRODUÇÃO}

Nesta introdução abordaremos o tema de estudo, a problemática enfrentada, as possíveis respostas a ela, os objetivos traçados, a justificativa para realização do estudo e, ao final, o procedimento metodológico. $\mathrm{O}$ desenvolvimento deste capítulo divide-se em outras quatro seções. Na segunda seção apresentam-se as "Políticas públicas municipais de emprego, trabalho e renda”. A seção três aborda o "Município, Mercado de trabalho e desenvolvimento local”. Na seção quatro, antes de introduzir o objeto deste trabalho, caracterizam-se e contextualizam-se os municípios e, à luz da experiência local, identificam-se as políticas de emprego, trabalho e renda, procurando compreender a prioridade frente as demais áreas. $\mathrm{E}$ a seção cinco apresenta algumas considerações finais.

É conveniente esclarecer que este capítulo aborda as políticas públicas de emprego, trabalho e renda numa perspectiva municipal, procurando compreender as ações dessa esfera, esquecida muitas vezes de estudos, 
devido à dificuldade de captação de dados junto às administrações municipais, refletindo numa incipiência do tema políticas públicas, em especial quando falamos de políticas públicas de emprego, trabalho e renda, uma vez que possuem como seu maior promotor a União e os estados.

Em apertada síntese, o capítulo procura compreender a prioridade que as políticas de emprego, trabalho e renda possuem frente as demais áreas, no âmbito das administrações municipais, as quais têm a responsabilidade de formular, planejar, implementar e avaliar políticas públicas que atinjam os propósitos do Estado, como organização necessária para a promoção do bem-estar social e do desenvolvimento.

O estudo parte da problemática - "Qual a prioridade que as políticas públicas municipais de emprego, trabalho e renda possuem frente as demais políticas?" - e para que seja possível respondê-la identificamos as políticas e as áreas para, posteriormente, com a comparação dos dados de investimento dos municípios, apresentando características do processo de concepção, aprovação e implementação de políticas públicas, bem como sua importância para o gerenciamento dos processos, percebermos melhor como as políticas públicas são geridas.

Norteiam o caminho deste estudo as seguintes questões: a) Os municípios têm realizado investimentos em políticas de emprego, trabalho e renda; b) As políticas de emprego, trabalho e renda possuem prioridade em relação às demais políticas públicas; c) As políticas de emprego, trabalho e renda contribuem para a desenvolvimento dos municípios e para o estímulo do mercado de trabalho local.

Para isso, num primeiro momento, as políticas de emprego, trabalho e renda são conceituadas, caracterizadas e tipificadas. Após, com os dados secundários, procuramos compreender a prioridade estabelecida pelos governos municipais na área do trabalho, estabelecendo uma comparação com as demais áreas. A análise comparativa não analisa o desempenho, mas a prioridade de investimento na área do trabalho nos municípios. 
O estudo justifica-se pela identificação da necessária intervenção nessa área, por meio de políticas públicas, em decorrência da incapacidade que os mercados, por si só, têm demonstrado na geração do desenvolvimento e de equidade (COHN, 1995). As dinâmicas que o acompanham deixam à margem trabalhadores menos capacitados, em desvantagem ou excluídos do mercado. Essas políticas apontam para a incapacidade do mercado de prover o pleno emprego.

A partir dos dados secundários, coligidos dos planos plurianuais e balanços contábeis dos Municípios de Cruz Alta, Ijuí, Santo Ângelo e Santa Rosa, no período de 1991 a 2000, identificamos as políticas públicas e as áreas que possuem investimentos. E para apurar a prioridade que as políticas públicas de emprego, trabalho e renda possuem frente as demais áreas, os balanços contábeis do período de 1991, 2000 e 2010. Nossa proposta não é uma análise minuciosa dos dados, mas, por meio desses dados, apresentar um panorama do investimento nas políticas públicas e sua inserção na esfera municipal.

A metodologia de pesquisa está fundamentada em uma abordagem qualitativa e quantitativa de natureza teórico-conceitual, utilizando-se de pesquisa bibliográfica e documental como meio de investigação (GIL, 2005, p. 44). Quanto aos fins, a pesquisa pode ser classificada como descritiva, pois procura expor características de determinado fenômeno (políticas de emprego, trabalho e renda), estabelecendo relação entre variáveis (com as demais políticas) (GIL, 2005, p. 42).Quantitativa, ao analisar dados secundários, obtidos a partir de planos plurianuais e balanços municipais de final de gestão, e dados primários objetivando a caracterização dos Municípios (SAMPIERI, 2013, p. 31). Qualitativa, ao analisar dados bibliográficos já produzidos sobre o assunto, atribuindo significados aos fatos e compreendendo informações e processos, por meio da observação dos fenômenos, identificando, descrevendo e interpretando a realidade (SAMPIERI, 2013, p. 376). A coleta de dados ocorreu por meio de pesquisa bibliográfica, documental e internet. A amostra foi composta por dados secundários retirados 
dos planos plurianuais (PPA's) dos municípios de Cruz Alta, Ijuí, Santo Ângelo e Santa Rosa, no período de 1991 até 2000, e dos balanços contábeis dos anos de 1991, 2000 e 2010, comparando os dados e identificando as prioridades nos orçamentos dos municípios objetos da pesquisa.

\section{POLÍTICAS PÚBLICAS MUNICIPAIS DE EMPREGO, TRABALHO E RENDA}

Para alcançar o objetivo proposto, nesta seção, o estudo se preocupa em expor conceitualmente e tipologicamente as políticas de emprego, trabalho e renda, apresentando o gerenciamento de seu processo.

O baixo nível de escolaridade e a capacitação nas populações mais carentes, em conjunto com um aumento das exigências para ingresso no mercado de trabalho, explicam, em parte, uma maior incidência do desemprego sobre certas populações (CHAHAD, 2003, p. 210). Os indicadores de desigualdade social, a discussão sobre a reforma do Estado, caracterizado como ineficiente, provocam o debate sobre as políticas públicas, em especial as sociais, e a relação Estado, Sociedade e Mercado (COHN, 1995, p. 3).

O protagonismo do Estado como agente de intervenção na resolução dos problemas públicos está na atuação de forma eficiente. As políticas públicas representam o Estado em ação (HOFLING, 2001, p. 31). A sociedade e suas relações sociais em constante mudança direcionam a Administração Pública a manter-se também em constante movimento, adequando-se à realidade de uma Administração Pública capaz, eficiente e que respeite os princípios constitucionais, promovendo políticas públicas que atendam às necessidades e anseios sociais.

A Organização Internacional do Trabalho (OIT) afirma que "o emprego é um direito de todos e cabe ao Estado garanti-lo, através de políticas públicas". Seguindo essa mesma compreensão, a Declaração Universal dos Direitos Humanos, em seu artigo 23, inciso I, afirma que "toda pessoa 
tem direito a escolha livre do emprego, bem como a condições justas e favoráveis, e à proteção contra o desemprego". Para atingir tal propósito, o Estado precisa intervir ativamente por meio de políticas públicas.

A preocupação com políticas sociais é algo muito recente no Brasil. Durante quase toda sua história acreditava-se que a questão social e a melhoria das condições de vida da população seriam um simples subproduto do crescimento econômico (JACCOUD, 2005, p. 182). Num breve retrospecto, é possível identificar que a legislação na área do trabalho passou por períodos históricos importantes: a criação do Ministério do Trabalho (1930), a CLT (1943), o FGTS (1966), o SINE (1976), o seguro-desemprego (1986) e a principal intervenção com a regulamentação do Fundo de Amparo ao Trabalhador (1990).

Diante das reformas do Estado, as políticas de emprego, trabalho e renda seguem a mesma lógica das outras áreas, apresentando, em geral, algumas características, como a descentralização para os níveis local, a participação de órgãos da sociedade civil e a prevalência de segmentos da população mais vulneráveis.

O campo das políticas públicas de emprego no Brasil segue de perto as tendências atuais em outras áreas da política social, entre as quais pode-se destacar três grandes movimentos: $a$ ) a descentralização das políticas para os níveis locais, englobando a atuação de estados e municípios; $b$ ) a terceirização, ou aumento da participação não-estatal na execução das políticas públicas de emprego, trabalho e renda, notadamente nos campos da intermediação de mão de obra e qualificação profissional; e c) a focalização dessas políticas sobre os grupos sociais considerados mais vulneráveis às transformações econômicas em curso (IPEA, 2006, p. 437).

O Estado é o local onde se exerce a cidadania e, ao mesmo tempo, é o promotor dessa cidadania, quando a sociedade não consegue por si só atingi-la. São os municípios que, na maioria das vezes, implementam as políticas públicas, que, em conjunto com a sociedade, enfrentam questões 
econômicas, socioculturais e de educação, com ações que melhorem, estimulem e desenvolvam a prestação do serviço público, por meio de uma gestão participativa e democrática.

Considerando que atualmente o processo de democratização e descentralização administrativa pela União tem se intensificado, a formulação e a implementação de políticas públicas e a responsabilidade de geri-las têm aumentado consideravelmente as atribuições dos municípios, abrindo novas possibilidades para o entendimento do local e das políticas sociais no país (ROTTA, 2007, p. 296).

No Brasil, concomitantemente com o que ocorreu no resto do mundo, as políticas de emprego, trabalho e renda têm adquirido maior importância e passaram a ser vistas como alternativas para garantir um mínimo, diante das mudanças em andamento. Esse fato se deve às transformações ocorridas na economia mundial, resultado das crises, com efeitos sobre as regras trabalhistas e funcionamento do mercado de trabalho (RAMOS, 2015, p. 41).

Em uma breve delimitação conceitual, as políticas de emprego, trabalho e rendasão aquelas que incidem mais diretamente sobre o mercado de trabalho e compreendem algumas ações, como qualificação profissional, intermediação de mão de obra e o seguro-desemprego. Medidas que objetivam contribuir para a estruturação e o melhor funcionamento do mercado de trabalho, podendo influenciar no nível de emprego, porém, de forma limitada (SILVEIRA, 2007, p. 189).

O planejamento é a decisão sobre as prioridades e necessidades que afetam a vida. O foco na política pública decorre do pressuposto de que o gerenciamento do processo tem significativa parcela de responsabilidade sobre o sucesso ou não de uma política pública, e sobre sua sustentabilidade ao longo da história. E para que se possa ter um bom gerenciamento, faz-se necessário um estudo e um planejamento antes do Estado mover-se na direção de promover políticas sociais, o que passa pela gestão das políticas públicas. 
No processo de gerenciamento das politicas públicas é possível identificar cinco etapas essenciais: definição de agenda (identificação da necessidade, elaboração da agenda); formulação; tomada de decisão; implementação; e avaliação (WU, 2014, p. 21-24).

\begin{abstract}
Nessa concepção, as atividades das políticas não ocorrem em "estágios”, com uma progressão linear de um para o outro. Ao contrário, são conjuntos de atividades discretas, embora inter-relacionadas, em que os gestores públicos podem se envolver para alcançar os objetivos das políticas da sua sociedade e do seu governo (WU, 2014, p. 21).
\end{abstract}

Brevemente, passaremos por cada uma dessas etapas, para compreendermos de que forma são concebidas as políticas públicas. Primeiramente, a definição de agenda passará pela identificação do problema, a partir da sua percepção em meio à sociedade, uma insatisfação com algo que se acredita ser questões de relevante interesse público e a respeito das quais o governo deve fazer algo. É um momento crucial no processo de elaboração de uma política que mitigará ou diminuirá as consequências negativas desse problema. Identificado o problema, a agenda é definida, estabelecendo-se, a partir do conjunto de problemas ou temas entendidos como relevantes, quais serão as prioridades (SECCHI, 2013, p. 45-47).

A formulação de políticas públicas envolve a construção de alternativas para possíveis cursos de ação governamental destinadas a tratar de problemas na agenda do governo. Com a introdução do problema na agenda, os esforços de desenvolvimento e combinação de soluções para os problemas são cruciais, e os formuladores de políticas enfrentam janelas de oportunidade para encontrar soluções viáveis (WU, 2014, p. 22).

A tomada de decisão é a etapa que sucede a formulação de alternativas de solução e representa o momento em que os interesses dos autores são equacionados e os objetivos e métodos de enfrentamento de um problema público são explicitadas. A tomada da decisão envolve indivíduos ou 
grupos oficialmente autorizados que decidem adotar um determinado curso de ação para a próxima etapa de implementação (SECCHI, 2013, p. 51).

O momento de implementação ou execução da política é um processo dinâmico e não linear, quando a política ganha forma e entra em vigor, e as decisões se traduzem em ações e onde qualquer deficiência na concepção das políticas ou qualquer vulnerabilidade relacionada ao ambiente externo se tornarão visíveis (WU, 2014, p. 97). Segundo Secchi, é neste arco temporal que são produzidos os resultados concretos da política pública (2013, p. 55). É a fase em que a Administração Pública se reveste de sua função precípua: executar as políticas públicas (2013, p. 57).

E, por fim, e não menos importante, a fase de avaliação, que envolve a apreciação do grau que a política pública está atingindo, com relação aos seus objetivos e, se não estiver, o que pode ser feito para melhorá-la. É o momento em que se pode identificar tanto deficiências quanto medidas corretivas. No entanto, tal potencial é muito inexplorado, uma vez que a avaliação pode oferecer uma linha crítica de defesa contra tais deficiências, pela investigação sistemática da eficácia de políticas, programas e procedimentos (WU, 2014, p. 24, 117).

Analisado o processo de gerenciamento de políticas públicas, ainda que sucintamente, foi possível compreender o seu processo de concepção. Com relação às políticas na área do trabalho, em que pese a sua necessidade, elas ainda são reduzidas, e a definição a seu respeito ainda não são consenso nos manuais, sendo possível identificar duas espécies: ativas e passivas. Para o IPEA, "As atividades dos sistemas de emprego estavam articuladas em torno de políticas passivas (seguro-desemprego) ou políticas ativas (intermediação e capacitação) pelo lado da oferta do mercado de trabalho" (IPEA, 2006, p. 436).

Resumidamente, as políticas passivas (reativas) possuem um caráter compensatório, consideram o nível de emprego ou desemprego como um dado, e o objetivo é amparar o trabalhador excluído do mercado de trabalho. Os instrumentos dessas políticas são seguro-desemprego e/ou indenização 
aos desligados e programas assistenciais para aqueles que não possuem acesso ao seguro-desemprego (AZEREDO, 1995, p. 94). De outro lado, as políticas ativas procuram intervir efetivamente na demanda por trabalho e na qualidade da oferta, ou seja, foco na empregabilidade. Os instrumentos desse tipo de política são, entre outros exemplos: criação de empregos públicos; investimentos emergenciais nas frentes de trabalho; subsídios públicos à contratação; oferta de crédito para empresas; redução de jornada de trabalho; e incentivos ao trabalho autônomo (AZEREDO, 1995, p. 95).

Na lógica de enfrentamento dos problemas sociais, em especial na área do trabalho, as políticas públicas com relação ao impacto esperado na sociedade se delineiam em políticas compensatórias que procuram desenvolver ações que possam minimizar distorções profundas (RUA, p. 51) e políticas regulatórias, que procuram priorizar, por exemplo, a formalização, facilitando o acesso ao crédito, criando uma maior interação entre os setores, o que expandiria o mercado e reduziria a evasão de divisas, combatendo a ilegalidade e resultando numa ampliação da arrecadação tributária (TOKMAN, 2003, p. 09).

As políticas de geração de emprego e renda podem fundamentar-se: a) no incentivo ao associativismo, cooperativismo, ou economia solidária; b) na qualificação profissional do trabalhador para ingressar ou se manter no mercado de trabalho ou como gestor do seu próprio negócio; c) em linhas de créditos para financiamento dos empreendimentos, entre outras (OLÍMPIO, p. 876). Como condutoras de uma nova concepção de políticas de geração de trabalho e renda, as políticas de economia solidária estimulam um outro tipo de desenvolvimento, o local (ARAUJO, 2005, p. 68-69). A economia solidária, sob diferentes formas associativas (associações, cooperativas, incubadoras e outras), podem promover, em que pese os ganhos serem muitas vezes modestos, para aquele indivíduo em vulnerabilidade econômica e social, a possibilidade de sustentar-se com o próprio trabalho, a partir de sua inclusão na economia (ASSEBURG, 2007, p. 528). 


\section{MUNICÍPIO, MERCADO DE TRABALHO E DESENVOLVIMENTO LOCAL}

Segundo André Franco Montoro (ex-governador do estado de São Paulo), "Ninguém mora na União, ninguém mora no Estado, todos moram no Município". Partindo dessa concepção, identificamos no Município o ente mais próximo ao cidadão, onde ele reside e desenvolve suas atividades, justificando a delimitação pela esfera municipal.

Considerando que pobreza, desigualdade e exclusão social representam fenômenos distintos, mas indissociáveis, o sentido da exclusão social aqui utilizado diz respeito à exclusão do mercado de trabalho, desencadeada por vários fatores, que apontam a crise econômica como um elemento de grande interferência no mercado de trabalho (NATIVIDADE, 2011, p. 03). É nesse contexto que situamos as políticas municipais de emprego, trabalho e renda, como promotoras de condições para manutenção do emprego, a geração de novos postos de trabalho, e o desenvolvimento do país, em especial dos municípios (MENESES, p. 13).

É importante compreender a realidade local quando se pensa em emprego, trabalho e geração de renda, verificando as necessidades do Município para pensar-se numa política eficaz, que não só prepare para o mercado em geral, mas também para as necessidades locais das pessoas nele inseridas.

O Município, pela proximidade com os cidadãos, possui maior conhecimento das necessidades locais, favorecendo uma maior compreensão das demandas, bem como maior agilidade na adoção de estratégias. Muito embora sua capacidade de ação esteja condicionada pela baixa capacidade fiscal, salvo raros casos de municípios maiores, deve-se destacar que existe um espaço crescente para iniciativas que podem estimular o desenvolvimento. São ações que, na maioria das vezes, podem se constituir pelas parcerias com empreendedores, sindicatos, associações empresariais, organizações 
da sociedade civil, agências de financiamento e fomento e instituições de ensino, pesquisa e assistência técnica (GUIMARÃES, 2011, p. 331).

[...] a ideia de desenvolvimento nasceu associada ao projeto da modernidade que previa a emancipação do ser humano e da sociedade em relação aos preceitos da tradição, do pensamento mágico e da religião, através da afirmação da capacidade do ser humano gerir sua própria historicidade pelo uso da razão. A afirmação da modernidade rompeu as formas tradicionais de pertencimento e proteção social, exigindo a produção de novos mecanismos e instrumentos que deram origem às políticas sociais. Portanto, desenvolvimento e políticas sociais são produtos da modernidade e como tais devem ser reconhecidos e analisados (ROTTA, 2007, p. 294).

Os municípios, reconhecendo a necessidade de integração entre as economias locais e os mercados globais, têm procurado formas de atrair empresas para seus territórios, em troca oferecendo benefícios financeiros, investimentos estruturantes, como distritos industriais, além de benefícios fiscais, na expectativa de retornos que consolidem um patamar desejável de desenvolvimento local, como um aumento no nível de emprego e um incremento da renda, criando um ambiente propício para o desenvolvimento econômico local (SOUSA, p. 9-10). Ao referir-se sobre desenvolvimento local, Rotta (2007) menciona que:

A compreensão de desenvolvimento foi se deslocando de uma mera reprodução, na esfera local, daquilo que ocorria em nível nacional, para uma postura mais ativa e propositiva, em termos de elaboração de projetos a partir das necessidades e demandas locais, com a participação dos atores locais (p. 297).

Ao retirar os municípios do isolamento e fortalecer sua capacidade de negociação, é possível identificar as potencialidades locais, como recursos naturais, capital humano, estimulando atividades produtivas complementares, visando adensar e agregar valor a cadeia produtiva, contribuindo significativamente para o desenvolvimento local. A oferta de microcrédito, 
a organização em cooperativas, a criação de incubadoras, a formação de consórcios com outros municípios, a regularização das terras para a organização dos produtores, o estímulo à comercialização, o acoplamento dos produtos locais às políticas de compras do Município, a organização de feiras, de centrais de comercialização, são alguns exemplos de ações por meio de políticas de emprego, trabalho e renda, que os municípios podem desenvolver melhor de que outro ente da federação (GUIMARÃES, 2011, p. 332-335).

No Artigo 203 da Carta Constitucional de 1988, a “inclusão socioprodutiva" é uma condição necessária para o desenvolvimento humano, pressupõe a inserção da população de baixa renda em todos os serviços prestados pelas diferentes políticas públicas. Já em seu preâmbulo, institui um Estado democrático de direito, cujos princípios são assegurar o desenvolvimento, a liberdade, a igualdade, a dignidade, e a justiça, como valores supremos de uma sociedade fraterna, pluralista e sem preconceitos, fundada nos os valores sociais do trabalho e na harmonia social.

A “inclusão socioprodutiva” coloca como um dos objetivos da assistência social a inserção da população beneficiária no mercado de trabalho (SIMÕES, 2009). Através da carta constitucional, o Brasil torna-se signatário da Declaração do Milênio que aponta entre os oito objetivos a necessidade de acabar com a fome e a miséria, e todo o mundo trabalhar pelo desenvolvimento.

Em uma Constituição social e democrática como a de 1988, o Estado não tem apenas o papel regulador. Além de intervir indiretamente na ordem econômica e social, diretamente presta serviços públicos. Com o advento do globalismo, e do desenvolvimentismo (BRESSER, 2007, p. 16-20) os governos federais, estaduais e municipais, em conjunto, têm o dever de promover políticas públicas de apoio ao contingente à margem do mercado de trabalho, tendência que já é possível ser destacada, em muitos municípios, como veremos ao longo do trabalho e também apresentada pelo IPEA (2006, p. 437). 
A reativação do mercado de trabalho foi um dos principais fatores na melhora da condição socioeconômica da população brasileira; no entanto, hoje é possível identificar que o mercado de trabalho novamente enfrenta dificuldades, e os motivos passam pela crise econômica e fiscal do Estado. Nesse contexto, em que o mercado não consegue regular, promovendo a igualdade e o pleno emprego, faz-se necessária uma intervenção social no campo das políticas públicas voltadas para o emprego (BALTAR, 2013). A crise do mercado de trabalho atualmente não se traduz apenas nos índices de desempregos, mas no contingente de pessoas que sobrevivem fora das condições de emprego formal, decorrente das mutações no modo de produção capitalista, com a qual as sociedades terão de conviver, sendo que o Estado deve promover a justiça social.

Os governos federal, estadual e municipal esforçam-se para promover políticas que estimulem a geração de renda e a criação e manutenção dos empregos. Existe um amplo leque de opções, como aquelas que apoiam as atividades informais, em outros tempos consideradas reflexo do atraso, além de incentivos para atrair empresas para suas áreas, como a construção de distritos industriais e subsídios para os investimentos.

Enquanto as lutas tradicionais se mostravam cada vez mais impotentes, as lutas locais-regionais demonstraram que era possível produzir uma contra-hegemonia ao movimento da globalização feita de cima para baixo. A valorização do espaço local-regional não pode ser entendida como uma nova apologia e nem como um "efeito-moda”, mas sim como o reconhecimento de que é em nível local que o desenvolvimento realmente ocorre (ROTTA, 2007, p. 295).

O desemprego e as demais condições que contextualizam a informalidade no mercado de trabalho devem ser preocupação do Estado. E os municípios, por estarem mais próximos desse mercado, devem comprometer-se compartilhadamente com a União e os estados na promoção de politicas 
públicas que reduzam essas desigualdades e promovam a justiça social. Em seu estudo, Rotta (2007) constata que:

[...] a perspectiva da territorialização do desenvolvimento, afirmando a especificidade dos espaços locais na definição das condições do desenvolvimento e apontando para os problemas decorrentes das opções globalizadoras. Nessa abordagem, as políticas sociais são vistas como elementos ativos e integrantes do processo de desenvolvimento e não como mecanismos compensatórios ou como estratégias de competição. [...] As políticas sociais são fundamentais tanto para auxiliar na criação das condições para o crescimento econômico quanto para efetivar mecanismos que possibilitem ampliar, gradativamente, a qualidade de vida da população (p. 296).

É importante, portanto, que ocorra o acompanhamento dos investimentos municipais em políticas sociais que possibilitem a melhoria da qualidade de vida da população.

\section{PANORAMA DO INVESTIMENTO DOS MUNICÍPIOS DO NOROESTE DO ESTADO DO RS}

A partir de pesquisa bibliográfica, identificamos na tese de doutorado de Rotta (2007) dados secundários, que fazem parte dos Planos Plurianuais $^{1}$ e Balanços Municipais de final de gestão dos anos de 1991 a 2000, que subsidiam nosso estudo, possibilitando a identificação e a compreensão de qual a prioridade que as políticas públicas municipais de emprego, trabalho e renda possuem frente as demais políticas e/ou áreas sociais ${ }^{2}$.

Os dados secundários foram atualizados para o ano de 2010 e posteriormente disponibilizados pelo coordenador do projeto "Políticas sociais

1 O Plano Plurianual deve ser elaborado no primeiro ano de mandato de uma legislatura, tendo validade para os três anos seguintes da mesma e o primeiro ano de mandato da legislatura posterior

$2 \mathrm{Na}$ análise que o autor faz, este explicita que dá prioridade às proposições direcionadas para políticas sociais de educação, saúde, trabalho, habitação e assistência social. Diante da enormidade de proposições presentes nessas cinco áreas de políticas sociais, nos três Planos Plurianuais analisados, opta-se por uma análise mais global de cada área. 
e desenvolvimento regional: o Noroeste do estado do Rio Grande do Sul na década de 2000"3.

O critério de definição dos municípios segundo Rotta foi o seguinte:

Definiram-se como os principais municípios da região aqueles que polarizam cada uma das quatro microrregiões, quer por sua importância econômica, sua origem histórica, seu contingente populacional, sua influência política e sócio-cultural. Sendo assim, procede-se o estudo dos municípios de Cruz Alta, Santo Ângelo, Ijuí e Santa Rosa (ROTTA, 2007, p. 209).

Em apertada síntese, caracterizamos os municípios a partir dos dados obtidos no IBGE e do levantamento feito no trabalho de Rotta (2007), observando a sequência histórica de fundação do município, iniciando por Cruz Alta e, posteriormente, Santo Ângelo, Ijuí e Santa Rosa.

O município de Cruz Alta possui uma área geográfica de 1.360,289 $\mathrm{Km}^{2}$ e abrigava, em 2010, uma população estimada de 62.821 habitantes (IBGE, 2016).

O município de Cruz Alta foi o primeiro a constituir-se no noroeste gaúcho.[...] O município de Cruz Alta se constituía assim com a maior extensão geográfica dos 14 municípios gaúchos existentes em 1834 [...] Dessa extensa área se constituiu a maior parte dos municípios do atual noroeste gaúcho, entre eles, Santo Ângelo, Ijuí e Santa Rosa, também objetos desse estudo comparativo. (ROTTA, 2007, p. 211).

Santo Ângelo foi o segundo município a constituir-se no noroeste gaúcho; apresenta atualmente uma área geográfica de $680,498 \mathrm{~km}^{2}$ e abrigava, em 2010, uma população estimada de 76.275 habitantes (IBGE, 2016).

A constituição do município de Ijuí está relacionada com o processo de expansão da fronteira agrícola para o noroeste gaúcho (ROTTA, 2007,

3 Projeto em execução e coordenado por Edemar Rotta, aprovado no Edital FAPERGS 02/2014 - PqG, com vigência de 19/12/2014 a 19/12/2016. "Políticas sociais e desenvolvimento regional: o Noroeste do Estado do Rio Grande do Sul na década de 2000”. 
p. 215). O atual município de Ijuí possui uma área territorial de 689,387 $\mathrm{km}^{2}$ e abrigava, em 2010, uma população estimada de 78.915 habitantes (IBGE, 2016).

O atual município de Santa Rosa possui uma área territorial de 489,798 $\mathrm{km}^{2}$ e abrigava, em 2010, uma população estimada de 68.587 habitantes (IBGE, 2016).

A recuperação histórica de algumas políticas de emprego, trabalho e renda contribuem para contextualizar e descortinar aspectos relevantes da tipologia das políticas públicas ${ }^{4}$. Para isso, serão evidenciadas algumas ${ }^{5}$ políticas públicas na área do trabalho, identificadas por Rotta (2007, p. 222-251) nos PPAs das cidades que foram objeto de pesquisa, durante o período compreendido entre 1991 e 2000.

No PPA que compreende o ano de 1991-93, os quatro municípios apresentam proposições de investimento direcionadas para qualificação dos servidores municipais e manifestaram uma preocupação com a geração de novos empregos, porém não consta nenhuma referência específica de políticas de emprego, trabalho e renda. Destacam-se os Município de Ijuí, apresentando uma preocupação em atrair novas empresas, e o $\mathrm{Mu}$ nicípio de Santa Rosa, apontando para uma necessidade de capacitar os trabalhadores e empresários.

No período de 1994-97, as prioridades mantêm-se quase as mesmas do período anterior, direcionadas aos servidores municipais, à geração de novos empregos e à atração de novas indústrias (Ijuí). O Município de Santa Rosa destaca-se apresentando uma preocupação com a prevenção de acidentes de trabalho, formação de mão de obra qualificada para a indústria, e incentivo à atividade industrial e redução do desemprego.

4 Segundo Rotta (2007, p. 222), dada à formatação diferenciada com que os planos se apresentavam em cada município, procedeu-se a organização das áreas e a redação das prioridades de forma a permitir uma visão clara da intenção expressa na proposta estabelecida, procurando manter, ao máximo, a redação original.

5 Em que pese o pesquisador apresentar um quadro sistematizado com todas as políticas relacionadas à área do trabalho, optamos por pinçar as principais políticas identificadas direitamente com a área do trabalho. 
Quatro anos à frente, no período que compreende os anos de 1998-2001, o painel não apresenta alterações em relação à direção das proposições contemplando os servidores municipais. Importante referência surge no PPA do Município de Ijuí, apresentando uma primeira perspectiva de investimento em políticas de emprego, trabalho e renda, quando apresenta uma proposta de criação de um cadastro permanente de empregados e uma secretaria especial de combate ao desemprego. O Município de Santa Rosa propõe investimentos na implantação de um centro de referência em saúde do trabalhador.

Após identificarmos algumas políticas dos municípios na área social, passamos à análise da sua execução orçamentária ${ }^{6}$, seguindo com base nos dados coletados por Rotta (2007, p. 255-268) em sua pesquisa nos municípios da região noroeste do Estado do Rio Grande do Sul, procurando compreender qual a prioridade que as políticas públicas municipais de emprego, trabalho e renda possuem frente às demais.

No período que compreende os anos de 1991-93, chamou a atenção na execução orçamentária ${ }^{7}$ que apenas Santo Ângelo, com 0,8\% em 1993, e Santa Rosa, com 1,69\% em 1991, 1,02\% em 1992, 2,08\% em 1993, apresentam um pequeno percentual de investimento na área do trabalho.

[...] A área de trabalho demonstra uma tendência que vai se manter ao longo da década, ou seja, a de ser a área de políticas sociais que recebe o menor montante de recursos investidos nos municípios pólo da região (ROTTA, 2007, p. 265).

No período de 1994-97, houve um aumento significativo de investimento na área do trabalho, direcionados por políticas de emprego, trabalho e renda, com exceção do Município de Ijuí, que mesmo tendo proposto em seu PPA investimentos na área do trabalho, nada investiu, repetindo o período

6 Percentual calculado sobre o total de investimento apurado nos balanços contábeis dos Municípios.

7 Salutar enfatizar, sem desrespeitar a atenta compreensão do leitor, que a partir deste momento, analisamos a execução orçamentária dos municípios objetos da pesquisa, pois em momento anterior analisávamos as proposições de execução, as previstas nos Planos Plurianuais de investimento. 
anterior. Os demais municípios fizeram os seguintes investimentos: Cruz Alta destaca-se com percentual médio de 5,36\% de seu orçamento; Santa Rosa, $1,22 \%$, aproximadamente o mesmo percentual de investimento do período anterior; Santo Ângelo, diferente do período anterior, passa a investir todos os anos do período um percentual médio de 1,49\% na área do trabalho.

Ao se verificar os acréscimos de investimentos mais significativos, destaca-se o caso de Santa Rosa, especialmente nas áreas de trabalho com 346,66\% com maior índice se comparado as demais áreas [...] Esses aumentos expressivos demonstram uma valorização maior das políticas sociais nas dinâmicas de desenvolvimento local, o que, em grande parte, também está expresso nos Planos Plurianuais do período (ROTTA, 2007, p. 267).

No próximo período, que compreende os anos de 1998-2000, Ijuí mantém a tendência, não investindo na área do trabalho, mesmo sinalizando investimentos em seus PPAs. Cruz Alta é município que apresenta maior investimento, mantendo uma média de $4,20 \%$, seguido de Santa Rosa, que mantém os investimentos na área do trabalho, com uma média de 1,60\% do orçamento compreendido no período. E Santo Ângelo mantém o investimento, aproximando-se de uma média de 0,96\%, apresentando uma redução comparado ao período anterior.

Chama a atenção o fato de que os investimentos diminuíram nos quatro municípios $[\ldots]$ na área de trabalho (nessa última, o município de Ijuí não diminuiu, pois não teve nenhum investimento apresentado em toda a série da década). Essa diminuição dos investimentos contrasta com o estabelecido nos Planos Plurianuais [...]. Para a área do trabalho, esse fato consolida a tendência constatada ao longo de toda a década, a inexistência de programas e ações para essa área de políticas sociais, especialmente nos seus Planos Plurianuais. Ao considerar-se a realidade de crise econômica e necessidade de buscar alternativas, significa um equívoco a não priorização dessa área (ROTTA, 2007, p. 268). 
Ao final, buscando identificar o grau de prioridade das políticas de emprego, trabalho e renda, apresenta-se um comparativo entre três anos, período que corresponde às últimas três décadas (1991, 2000 e 2010). O comparativo é feito conforme a prioridade dada pela pesquisa às políticas sociais (ROTTA, 2007), com dados que vão compor o projeto "Políticas sociais e desenvolvimento regional: o Noroeste do estado do Rio Grande do Sul na década de 2000". Analisa-se o percentual de investimentos de cada área, com base no total investido nos anos de 1991, 2000 e 2010, destacando-se a área de trabalho.

O Quadro 1 apresenta o percentual de investimento das respectivas áreas sociais, comparado ao total de investimento retirado dos balanços contábeis dos municípios.

Quadro 1 - Percentual de investimentos nas áreas sociais - 1991, 2000 e 2010

\begin{tabular}{|c|c|c|c|c|c|c|c|}
\hline Ano & Município & $\begin{array}{l}\text { Educ. e } \\
\text { Cultura }\end{array}$ & $\begin{array}{l}\text { Habit. e } \\
\text { Urb. }\end{array}$ & $\begin{array}{l}\text { Assist. e } \\
\text { Previd. }\end{array}$ & Trabalho & Saúde & Total Investimento \\
\hline 1991 & Cruz Alta & 32,79 & 59,33 & 7,88 & 0,00 & 0,00 & $\mathrm{R} \$ 15.205 .737,97$ \\
\hline 1991 & ljuí & 50,97 & 12,78 & 24,57 & 0,00 & 11,67 & $\mathrm{R} \$ 17.267 .735,13$ \\
\hline 1991 & Santa Rosa & 47,58 & 11,83 & 20,18 & 2,29 & 18,11 & $R \$ 20.350 .556,98$ \\
\hline 1991 & Santo Ângelo & 47,01 & 28,27 & 19,14 & 0,00 & 5,58 & $\mathrm{R} \$ 20.029 .466,89$ \\
\hline 2000 & Cruz Alta & 41,61 & 26,97 & 6,73 & 5,50 & 19,18 & $\mathrm{R} \$ 45.385 .329,74$ \\
\hline 2000 & ljuí & 46,08 & 8,19 & 17,22 & 0,00 & 28,5 & $\mathrm{R} \$ 58.587 .233,83$ \\
\hline 2000 & Santa Rosa & 33,69 & 6,48 & 14,82 & 1,90 & 43,1 & $\mathrm{R} \$ 69.852 .088,96$ \\
\hline 2000 & Santo Ângelo & 46,94 & 9,49 & 20,93 & 1,46 & 21,18 & $\mathrm{R} \$ 50.368 .924,45$ \\
\hline 2010 & Cruz Alta & 43,19 & 10,81 & 11,24 & 0,02 & 34,74 & $\mathrm{R} \$ 61.060 .811,86$ \\
\hline 2010 & ljuí & 34,32 & 8,78 & 21,93 & 0,00 & 34,97 & $\mathrm{R} \$ 92.987 .499,91$ \\
\hline 2010 & Santa Rosa & 35,71 & 3,72 & 12,61 & 1,21 & 46,76 & $\mathrm{R} \$ 97.682 .753,74$ \\
\hline \multirow[t]{2}{*}{2010} & Santo Ângelo & 38,23 & 18,02 & 19,22 & 0,00 & 24,53 & $\mathrm{R} \$ 90.814 .489,16$ \\
\hline & Média & 41,51 & 17,06 & 16,37 & 1,03 & 24,03 & \\
\hline
\end{tabular}

Fonte: Elaborado pelos autores, 2017.

8 Projeto em execução e coordenado por Edemar Rotta, aprovado no Edital FAPERGS 02/2014 - PqG, com vigência de 19/12/2014 a 19/12/2016, intitulado Políticas sociais e desenvolvimento regional: o Noroeste do estado do Rio Grande do Sul na década de 2000. 
O crescimento dos investimentos é significativo nas cinco áreas sociais em praticamente todos os municípios. O município de Ijuí permanece, ao longo dos três períodos, sem nenhum investimento na área do trabalho, o que significa uma incoerência com relação ao estabelecido em seus Planos Plurianuais. Os maiores crescimentos do montante investido, em termos percentuais, ocorrem na área do trabalho, com um acréscimo de 876,95\%; no entanto, é a área que apresenta os menores valores totais.

Ao analisar cada um dos municípios, nas cinco áreas de políticas sociais, é possível identificar que, ao final dos três períodos, o menor percentual de investimento ocorre em políticas de emprego, trabalho e renda, contrastando com a real necessidade de investimento nessa área social.

[...] Essa falta de investimentos na política social de trabalho contrasta com a necessidade que existia, nessa mesma época, de buscar soluções para um ambiente de crise econômica e falta de empregos que a região vivia. Essa falta de investimentos pode estar relacionada com a concepção existente na região a respeito dessa política (ela ser de atribuição do governo federal) [...] (ROTTA, 2007, p. 257).

O percentual de investimento médio total dos três períodos, nos quatro municípios, é de 41,51\% em Educação e Cultura, Saúde com cerca de 24,03\%, seguido de 17,06\% em Habitação e Urbanismo, 16,37\% em Assistência e Previdência e, por fim, a área de trabalho com 1,03\%.

\section{CONSIDERAÇÕES FINAIS}

A decisão de abordar o tema em destaque partiu da necessidade acadêmica de compreender, partindo de uma visão de desenvolvimento e de políticas públicas, se na esfera municipal existem políticas públicas direcionadas à área do trabalho. E compreender qual sua prioridade frente as demais áreas, uma vez que tais políticas geralmente são promovidas pela 
União ou pelos estados, na busca pela promoção e/ou proteção do emprego e dos trabalhadores.

Ao final, foi possível concluir que alguns municípios têm se preocupado com investimentos em políticas de emprego, trabalho e renda, todavia, são ainda muito incipientes no âmbito municipal, o que podemos notar a partir dos baixos investimentos nesse tipo de políticas, muito embora tenhamos verificado que tais políticas possuem papel importante no mercado de trabalho dos municípios.

\section{REFERÊNCIAS}

ARAÚJO, H. E. (Org.). Avaliação de políticas públicas de economia solidária. Brasília: MTE/IPEA/ANPEC, 2005. 93 p. Relatório Final.

ASSEBURG, H. B.; GAIGER, L. I. A economia solidária diante das desigualdades. Dados, Rio de Janeiro, v. 50, n. 3, p. 499-533, 2007.

AZEREDO, B.; RAMOS, C. A. Políticas públicas de emprego: experiências e desafios. Planejamento e Políticas Públicas, Rio de Janeiro, Ipea, n.12, p. 91-116, jun./dez. 1995.

BALTAR, P. Crescimento na economia e mercado de trabalho no Brasil. In: IPEA. Desafios para o desenvolvimento brasileiro. Brasília: Ipea, 2011.

BRESSER-PEREIRA, L. C.. Burocracia pública na construção do Brasil. Revista de Sociologia e Política, Paraná, n. 28, p. 9-30, 2007.

CHAHAD, J. P. Z. Tendências recentes no mercado de trabalho: pesquisa de emprego e desemprego. São Paulo em Perspectiva, v. 17, n. 3-4, p. 205-217, 2003.

COHN, A. Políticas sociais e pobreza no Brasil. Planejamento e Políticas Públicas, Ipea, n.12, jan./dez. 1995, p.1-17.

GAETANI, F. Políticas de gestão pública e políticas regulatórias: contrastes e interfaces. IX Congresso internacional del CLAD sobre la reforma del Estado y de la Administración Pública, Madrid, Espanha, p. 2-05, 2004.

GIL, A. C. Como Elaborar projetos de Pesquisa. 4. ed. São Paulo: Atlas, 2005. 
GUIMARÃES, A. Q. et al. Iniciativas para a promoção de emprego e renda: políticas públicas, economia solidária e desenvolvimento local.2011.

HÖFLING, E. de M. Estado e políticas (públicas) sociais. Cadernos Cedes, Campinas, v. 21, n. 55, p. 30-41, nov. 2001.

FUNDAÇÃO INSTITUTO BRASILEIRO DE GEOGRAFIA E ESTATÍSTICA (IBGE). Cidades. Brasília, 2016. Disponível em: <http://www.cidades.ibge. gov.br/xtras/home.php>Acesso em: 22 jun. 2016.

IPEA. Comunicado da Presidência $n^{\circ}$ 19. Emprego público no Brasil: Comparação internacional e evolução. Brasil: Ipea, 2009.

IPEA. Políticas Públicas de emprego, trabalho e renda no Brasil. In: TAFNEL, P. (Ed.). Brasil: O estado de uma nação. Mercado de emprego, trabalho e informalidade. Rio de Janeiro: Ipea, 2006, p. 398-446.

JACCOUD, L.; CARDOSO Jr, J. C.. Políticas sociais no Brasil: organização, abrangência e tensões da ação estatal. In: JACCOUD, L. (Org.). Questão social e políticas sociais no Brasil contemporâneo. Brasília: Ipea, p. 181-260, 2005.

MENESES, A. C. B. Manual "Município Empreendedor - Políticas Públicas de Trabalho, Renda e Empreendedorismo". Secretaria do Trabalho e Empreendedorismo e o Instituto de Desenvolvimento do Trabalho do Ceará. Fortaleza: IDT.

NATIVIDADE, E. A. et al. Gestão Social de Políticas Públicas de Geração de Trabalho e Renda: uma reflexão por meio das ações da Secretaria Nacional de Economia Solidária. APGS, Viçosa, v.3, n.1, pp. 1-22, 2011.

OlÍMPIO, J. de O; OlIVEIRA, E. A. de A. Q. Aplicação de políticas macroeconômicas para redução do desemprego. VIII Encontro Latino Americano de Iniciação Científica e IV Encontro Latino Americano de Pós-Graduação - Universidade do Vale do Paraíba. p. 875-880.

RAMOS, C. A. et al. Mercado de trabalho: conjuntura e análise. In: CORSEUIL, C. (Org.). A importância alocativa das políticas de emprego. Brasília: Ipea, p. 37-50, 2015.

ROTTA, E. Desenvolvimento regional e políticas sociais no noroeste do estado do Rio Grande do Sul. Porto Alegre, FSS/PUCRS, Tese de Doutorado, 2007.

RUA, M. das G. Para aprender políticas públicas. Curso on-line políticas públicas. Instituto de gestão e economia e políticas públicas - IGEPP.

SAMPIERI, R. H. et al. Metodologia de Pesquisa. 5. ed. São Paulo: Penso, 2013. 
SIlVEIRA, I. M. M. da. A Descentralização da Política de Assistência Social no Ceará: caminhos e descaminhos. UFPE. CCSA. Serviço Social. Tese de doutorado, 2007.

SIMÕES, L. G; PEIXOTO, N. M. Geração de emprego, trabalho e renda nos municípios paulistas. 2009.

SOUSA, D. Políticas públicas de trabalho, emprego e renda: as ações dos governos e as lógicas do apoio à informalidade e à carteira assinada. Disponível em: <http://www.cchla.ufrn.br/cnpp/pgs/anais/Arquivos\%20GTS\%20-\%20 recebidos\%20em\%20PDF/POL\%C3\%8DTICAS\%20P\%C3\%9ABLICAS\%20 DE\%20TRABALHO,\%20EMPREGO\%20E\%20RENDA.pdf $>$.

TOKMAN, V. De La informalidad a La modernidad. Montevidéo: Boletim Cinterfor, n.155, 2003.

WU, X. et al. Guia de políticas públicas: gerenciando processos. Tradução de Ricardo Avelar de Souza. Brasília: Enap. 2014. 